\title{
Stress granules and RNA processing bodies are novel autoantibody targets in systemic sclerosis
}

\author{
Michael E. Johnson' ${ }^{1}$, Andrew V. Grassetti ${ }^{1}$, Jaclyn N. Taroni', Shawn M. Lyons', Devin Schweppe ${ }^{1}$, Jessica K. Gordon²,
} Robert F. Spiera ${ }^{3}$, Robert Lafyatis ${ }^{4}$, Paul J. Anderson ${ }^{2}$, Scott A. Gerber ${ }^{1}$ and Michael L. Whitfield ${ }^{1,5^{*}}$

\begin{abstract}
Background: Autoantibody profiles represent important patient stratification markers in systemic sclerosis (SSc). Here, we performed serum-immunoprecipitations with patient antibodies followed by mass spectrometry (LC-MS/MS) to obtain an unbiased view of all possible autoantibody targets and their associated molecular complexes recognized by SSc.

Methods: HeLa whole cell lysates were immunoprecipitated (IP) using sera of patients with SSc clinically positive for autoantibodies against RNA polymerase III (RNAP3), topoisomerase 1 (TOP1), and centromere proteins (CENP). IP eluates were then analyzed by LC-MS/MS to identify novel proteins and complexes targeted in SSc. Target proteins were examined using a functional interaction network to identify major macromolecular complexes, with direct targets validated by IP-Western blots and immunofluorescence.

Results: A wide range of peptides were detected across patients in each clinical autoantibody group. Each group contained peptides representing a broad spectrum of proteins in large macromolecular complexes, with significant overlap between groups. Network analyses revealed significant enrichment for proteins in RNA processing bodies (PB) and cytosolic stress granules (SG) across all SSc subtypes, which were confirmed by both Western blot and immunofluorescence.

Conclusions: While strong reactivity was observed against major SSC autoantigens, such as RNAP3 and TOP1, there was overlap between groups with widespread reactivity seen against multiple proteins. Identification of PB and SG as major targets of the humoral immune response represents a novel SSc autoantigen and suggests a model in which a combination of chronic and acute cellular stresses result in aberrant cell death, leading to autoantibody generation directed against macromolecular nucleic acid-protein complexes.
\end{abstract}

Keywords: Systemic sclerosis, Scleroderma, Autoantibody, RNA processing bodies, Stress granules

\section{Background}

Systemic sclerosis (SSc) is a rare systemic autoimmune disease of unknown etiology characterized by skin fibrosis, internal organ involvement, vascular abnormalities, and autoantibody production. Patients are broadly classified as having either limited (ISSc) or diffuse (dSSc) disease based primarily upon the extent of

\footnotetext{
* Correspondence: michael.I.whitfield@dartmouth.edu

${ }^{1}$ Department of Genetics, Geisel School of Medicine at Dartmouth, Hanover, $\mathrm{NH}$, USA

${ }^{5}$ Dartmouth Medical School, Hinman Box 7400, Hanover, NH 03755, USA

Full list of author information is available at the end of the article
}

skin involvement and autoantibody profiles. While a wide array of autoantibodies have been described for SSc, only a small number of these targets are used for clinical diagnosis and stratification. Autoantibodies targeting RNA polymerase III (RNAP3), topoisomerase 1 (TOP1; commonly referred to as Scl70), and centromere proteins (CENP) represent the three the most common, clinically measured autoantibodies observed in SSc $[1,2]$. Other autoantibodies, including fibrillarin (U3RNP), Pm/Scl, Ku, U1RNP, U11/U12, and $\mathrm{Th} /$ To have also been described $[1,3]$ but are not routinely measured for clinical subtyping. 
While the processes underlying autoantibody production in SSc remain poorly understood, the presence of certain autoantibodies is strongly predictive of clinical outcomes [1-3]. TOP1 and RNAP3 autoantibodies are almost exclusively seen in dSSc, while CENP, Th/To, and U1RNP antibodies are more commonly associated with ISSc $[1,3]$. U3RNP autoantibodies are not associated with either clinical subset, and are often found in conjunction with other autoantibodies, including both TOP1 and CENP [3]. Certain antibodies, such as TOP1 and U11/12, have been shown to be predictive of poorer overall prognosis, including increased likelihood of pulmonary fibrosis [4] and cardiac involvement, while RNAP3 autoantibodies have recently been linked to cooccurrence of SSc with cancer [5].

Despite the importance of autoantibodies in SSc, the vast majority of target identification and phenotypic screening has been performed using methods targeting only a single autoantibody, with little ability to detect novel or low abundance autoantibodies. Furthermore, these methods fail to address the possibility of cooccurrence of multiple autoantibodies within a patient, which may have important clinical implications. Autoantigen microarrays have proven successful for screening large numbers of autoantibodies in parallel, however target identification is limited to those antigens produced and printed on the antigen microarrays [6]. To address these limitations, we performed immunoprecipitations (IP) of HeLa whole cell lysates using sera from RNAP3-, CENP-, and TOP1-positive patients, as well as healthy controls, followed by mass spectrometry (LC-MS/MS) to provide an unbiased assessment of all autoantibodies present in these SSc patients. This method provides a better view of the full range of autoantibodies present in SSc, including both novel and established targets, and provides insights into the general processes underlying autoantibody production.

\section{Methods}

\section{Clinical samples}

Patient serum was obtained from Boston University Medical School, Boston (BUMC), MA, USA and the Hospital for Special Surgery (HSS), New York, NY, USA. All relevant study protocols were approved by the Dartmouth College committee for the protection of human subjects, and the internal review boards of both BUMC and HSS. Informed consent was obtained from all patients prior to sample collection. Patients were diagnosed with either dSSc or limited SSc, as determined using the 1980 American College of Rheumatology classification criteria. Detection of major autoantibody reactivities was performed using standard clinical assays.

\section{Human cell lysates}

HeLa cells were cultured in DMEM supplemented with $10 \%$ fetal bovine serum (FBS) (v/v) and $100 \mathrm{IU} / \mathrm{mL}$ penicillin-streptomycin. Cells were grown to approximately $80 \%$ confluence, harvested in IP lysis buffer (150 mM NaCl, $50 \mathrm{mM}$ Tris $\mathrm{pH} 7.5,1 \mathrm{mM} \mathrm{MgCl} 2,1 \mathrm{mM}$ EDTA, $0.5 \%$ Triton X-100, $2.5 \mathrm{mM} \beta$-mercaptoethanol, $1 \mathrm{mM}$ sodium molybdate, $1 \mathrm{mM}$ sodium fluoride, $1 \mathrm{mM}$ sodium tartrate, $1 \mathrm{mM}$ dithiothreitol (DTT), and protease inhibitors (Roche, Indianapolis, IN, USA)), lysed by passage through a pre-chilled high-gauge syringe, and centrifuged for 15 minutes to pellet debris. Lysates were then clarified by incubating for $4 \mathrm{~h}$ at $4{ }^{\circ} \mathrm{C}$ on a rotating platform. Protein concentrations were quantified using a standard bicinchoninic acid (BCA) protein assay kit (Thermo Scientific, Waltham, MA, USA).

\section{Serum immunoprecipitation}

Patient serum was cross-linked to Protein G Dynabeads (Invitrogen, St. Louis, MO, USA) prior to IP. First, $100 \mu \mathrm{L}$ serum (approximately $1 \mathrm{mg}$ IgG) was added to $50 \mu \mathrm{L}$ Protein $\mathrm{G}$ beads and incubated for $5 \mathrm{~h}$ at $4{ }^{\circ} \mathrm{C}$. Samples were then washed in PBS, equilibrated in crosslinking buffer (50 mM HEPES, pH 8.2), and cross-linked to Protein $\mathrm{G}$ beads by the addition of $20 \mathrm{mM}$ dimethyl pimelimidate and $300 \mathrm{mM}$ HEPES (DMP) solution for 10 minutes at room temperature (repeated three times). The crosslinking reaction was then terminated by the addition of $50 \mathrm{mM}$ ammonium bicarbonate, and the resulting antibody bead mixture added to $500 \mu \mathrm{L}$ cell lysate (diluted to $4 \mathrm{mg} / \mathrm{mL}$ in IP lysis buffer). Samples were incubated overnight at $4{ }^{\circ} \mathrm{C}$ on a rotating platform, washed in cold IP lysis buffer, and eluted in a buffer containing $2 \%$ SDS, $75 \mathrm{mM} \mathrm{NaCl}, 50 \mathrm{mM}$ Tris $\mathrm{pH}$ 8.1, and $20 \%$ glycerol at $65{ }^{\circ} \mathrm{C}$ for 5 minutes. Eluates were reduced by the addition of $0.1 \mathrm{M}$ dithiothreitol (DTT) (to a final concentration $5 \mathrm{mM}$ ), and incubated at $80{ }^{\circ} \mathrm{C}$ for 5 minutes. Samples were then resolved by SDS-PAGE, split into high $(>60 \mathrm{kDa})$ and low $(<60 \mathrm{kDa})$ molecular weight fractions and analyzed by mass spectrometry.

\section{Mass spectrometry}

Proteins contained in Coomassie-stained gel regions were digested overnight with trypsin $(1: 200 \mathrm{w} / \mathrm{v})$ at $37^{\circ}$ C. Following digestion, peptides were extracted from the gels, dried, and analyzed by nanoscale LC-MS/MS. LCMS/MS analyses were performed on either LTQ Orbitrap Classic or Orbitrap Fusion LC-MS/MS platforms. LTQ Orbitrap Classic analyses were conducted as described previously [7].

For Orbitrap Fusion analyses, samples were loaded onto an EASY-nLC 1000 Liquid Chromatograph (Thermo Scientific, Waltham, MA, USA) and separated by reversephase high pressure liquid chromatography (RP-HPLC) 
using an approximately $36-\mathrm{cm}$ column with a $100-\mu \mathrm{M}$ inner diameter packed with $3 \mu \mathrm{m} 120 \AA \mathrm{C}_{18}$ particles (Dr. Maisch $\mathrm{GmbH}$, Ammerbuch-Entringen, Germany). The resultant peptide eluate was directed into an Orbitrap Fusion Tribrid Mass Spectrometer operating in a datadependent sequencing acquisition mode across a 30minute reverse-phase gradient (6\% acetonitrile, $0.1 \%$ formic acid to $30 \%$ acetonitrile, $0.1 \%$ formic acid) at $350 \mathrm{~nL} / \mathrm{min}$ flow rate. The Orbitrap Fusion was operated with an Orbitrap MS1 scan at $120 \mathrm{~K}$ resolution, followed by Orbitrap MS2 scans of higher energy collision-induced dissociation (HCD) fragment ions (30 \% HCD energy) at $15 \mathrm{~K}$ resolution using a maximum cycle type of $2 \mathrm{~s}$, precursor ion dynamic exclusion window of $15 \mathrm{~s},+2,+3$, and +4 precursor ions selected for LC-MS/MS, and maximum ion injection times of $100 \mathrm{~ms}$ (MS1) and $50 \mathrm{~ms}$ (MS2). The resulting tandem mass spectra were datasearched using the COMET search engine [8] against a Homo sapiens proteome database (source: Uniprot; download date: 2 July 2013) with a precursor ion tolerance of +/- $1 \mathrm{Da}$ [9] and a fragment ion tolerance of 0.02 Th. Peptide spectra matches (PSMs) were filtered to $<1 \%$ false discovery rate using the target decoy strategy [10], and reported.

\section{IP-western blots}

Anti-UPF1 antibody was kindly provided by Dr. Lynne Maquat (University of Rochester Medical Center, Rochester, NY, USA). Antibodies to MOV10 and CAPRIN1 were purchased from Proteintech (Chicago, IL, USA); antibodies to G3BP1 and USP10 were purchased from Santa Cruz Biotechnology (Santa Cruz, CA, USA). Serum immunoprecipitation of HeLa lysates was performed as described above; $50 \%$ of each eluate $(15 \mu \mathrm{L})$ was then run on a $10 \%$ bis-tris precast gel (Life Technologies, Carlsbad, CA, USA). HeLa whole cell lysate $(100 \mu \mathrm{g})$ was used as a positive control; no loading control was performed due to the absence of viable targets present in all IP eluates. Western blots were then run following standard protocols, and visualized using Western Lightning ECL Pro or Ultra substrate (Perkin Elmer Inc., Waltham, MA, USA), as necessary.

\section{Data analysis}

Non-redundant peptide hits, defined as mass spectra mapping exclusively to a given peptide fragment, were used for all downstream analyses. Pairwise comparisons between samples were performed by Fisher's exact test using the Bonferroni correction for multiple hypothesis testing. Venn diagrams were generated using VENNY [11]. Network analysis was performed using the Genomescale Integrated Analysis of gene Networks in Tissues (GIANT; http://giant.princeton.edu/) global network [12] and visualized using Cytoscape [13]. Communities in the network were detected using fast-greedy modularity as implemented in igraph. Functional annotation of individual communities was performed using g:Profiler [14]. Semiquantitative enrichment of SSc-associated autoantibodies was determined using a binary assessment of autoantibody presence or absence in a sample. Preferential enrichment in SSc was defined as all proteins detected in $>50 \%$ of all patient samples at a frequency $>1.5$ fold relative to controls. Enrichment of biological processes and cellular components was determined using g:Profiler using the g:SCS threshold correction for multiple hypothesis testing and a functional category size $\leq 500$ genes. Hierarchical clustering was performed using Cluster 3.0 [15], and visualized using Java TreeView [16].

\section{Immunofluorescence}

The day prior to the experiment, $10^{5} \mathrm{U} 2 \mathrm{OS}$ cells were seeded onto $11 \mathrm{~mm}$ glass coverslips and allowed to attach overnight at $37{ }^{\circ} \mathrm{C} / 5 \% \mathrm{CO}_{2}$ in DMEM containing $10 \%$ FBS (Gibco). Cells were treated with $100 \mu \mathrm{M}$ sodium (meta)arsenite (Sigma Aldrich) for $1 \mathrm{~h}$ to induce the formation of stress granules and then with $4 \%$ paraformaldehyde solution at room temperature for 15 minutes followed by blocking and permeabilization with $5 \%$ normal horse serum, $0.1 \%$ digitonin in Trisbuffered saline. Staining was performed with anti-eIF3b (Santa Cruz), anti-SK1-Hedls (Santa Cruz), and patient sera for $1 \mathrm{~h}$ at room temperature. Secondary antibodies (anti-goat-Cy3, anti-mouse-Cy2, and anti-human-Cy5) were purchased from Jackson Laboratories and incubated at room temperature for $1 \mathrm{~h}$. Conventional fluorescence microscopy was performed using a microscope (model Elipse E800, Nikon, Tokyo, Japan) with epifluorescence optics with a digital camera (model CCD-SPOT RT; Diagnostic Instruments, Sterling Heights, MI). Images were compiled using Adobe Photoshop software (CS6; Adobe Systems, San Jose, CA).

\section{Results}

Identification of proteins cross-reacting to serum antibodies Immunoprecipitations (IP) of HeLa whole cell lysates were performed using sera obtained from 13 SSc patients and 4 healthy controls. HeLa cells were chosen based upon their consistent, high level of expression of a broad range of proteins from the human genome [17].

SSc patients were divided into three groups, TOP1, RNAP3, and CENP, as measured in a reference laboratory; clinical data for each patient are shown in Table 1. These groups were chosen based upon their relative frequency, and their importance in clinical diagnosis. Immunoprecipitated proteins were analyzed by LC-MS/ MS, and the resulting spectra aligned to the reference human proteome (UCSC version hg19). Data are presented in two ways; first to identify the total number of 
Table 1 Clinical information for patients involved in this study

\begin{tabular}{|c|c|c|c|c|c|c|c|c|c|c|}
\hline Sample & Group & Age (years) & Sex & Race & Disease type & ILD/PAH & Disease duration (years) & ANA pattern & ANA titer & MRSS \\
\hline SSC 1 & TOP1 & 36 & $\mathrm{~F}$ & White & Diffuse & mild ILD & 2.5 & & $1: 320$ & 43 \\
\hline SSc 132 & TOP1 & 49 & $\mathrm{~F}$ & White & Diffuse & No & & Homogeneous & $1: 640$ & 27 \\
\hline SSc 218 & TOP1 & 55 & $\mathrm{~F}$ & White & Diffuse & ILD & & Homogeneous/nucleolar & $1: 2560$ & 18 \\
\hline SSc 208 & TOP1 & 64 & M & White & Diffuse & No & & Nucleolar & $1: 1280$ & 37 \\
\hline SSc 5 & RNAP3 & 53 & M & White & Diffuse & No & 0.75 & Speckled & $1: 80$ & 36 \\
\hline SSc 7 & RNAP3 & 45 & $\mathrm{~F}$ & Black & Diffuse & No & 0.5 & Speckled & $1: 80$ & 27 \\
\hline SSC 10 & RNAP3 & 52 & M & White & Diffuse & No & 0.5 & & 0 & 22 \\
\hline SSC 18 & RNAP3 & 69 & $\mathrm{~F}$ & White & Diffuse & ILD & 0.5 & Nucleolar & $1: 160$ & 44 \\
\hline SSC 159 & CENP & 54 & $\mathrm{~F}$ & Mixed & Limited & No & 7 & Centromere & $1: 1280$ & 2 \\
\hline SSC 177 & CENP & 64 & $\mathrm{~F}$ & White & Limited & No & 15 & Discrete speckled & $4+$ & \\
\hline SSC 194 & CENP & 66 & $\mathrm{~F}$ & White & Limited & No & 18 & Discrete speckled & $4+$ & 6 \\
\hline SSC 238 & CENP & 53 & $\mathrm{~F}$ & White & Limited & No & 6 & Centromere & $1: 640$ & 5 \\
\hline SSc 226 & CENP & 55 & $\mathrm{~F}$ & Asian & Diffuse & No & & Centromere & $1: 1280$ & 6 \\
\hline HC 162 & Control & 24 & M & White & & & & & & \\
\hline HC 400 & Control & 21 & M & White & & & & & & \\
\hline HC 117 & Control & & M & & & & & & & \\
\hline HC 118 & Control & & M & & & & & & & \\
\hline
\end{tabular}

Blank cells indicate information not available at the time of sample collection. ILD interstitial lung disease, $P A H$ pulmonary arterial hypertension, $A N A$ anti-nuclear antibody, MRSS modified Rodnan skin score, SSC systemic sclerosis, $M$ male, $F$ female

peptides that could be aligned to each protein (total hits), and second to identify all non-redundant peptides that mapped exclusively to a given protein (non-redundant hits). A complete list of all data can be found in Additional file 1: Table S1.

\section{Exclusivity and co-occurrence of SSc autoantibodies}

We observed a high degree of reproducibility between patients within their respective autoantibody groups (TOP1, RNAP3, and CENP; Fig. 1). The greatest degree of overlap between peptides was observed among RNAP3 patients (Fig. 1a and c), with 420 proteins (54.1\%) detected in all four patients (Fig. 1c). The remaining groups exhibited significant overlap in three of four (TOP1) and four of five (CENP) patients, respectively (Fig. 1a), along with a single outlier that showed either higher (SSc 208; TOP1) or lower (SSc 226; CENP) total peptide hits relative to other samples in these groups. Within TOP1, 111 proteins $(14.2 \%)$ were detected in all four patients (Fig. 1d), while CENP exhibited 48 proteins $(10.5 \%)$ common to all patients (Fig. 1c). The least overlap was seen in healthy controls, with only 40 proteins (7.6 \%; Fig. 1b) common across individuals.

Across all samples, 283 proteins (25.0\%) were detected in at least one patient in each of the four autoantibody groups (Fig. 1e, Additional file 2: Table S2). Some of these proteins likely represent background signals (serum albumin (ALB), $\beta$-tubulin (TUBB), and ribosomal proteins), while others are considered specific to SSc despite trace level detection in controls. For example, multiple SSc autoantibody targets, including $\mathrm{Ku}$ (XRCC5 and XRCC6), Ro52/TRIM21, and nucleophosmin/B23 (NPM1) were present in this set of proteins. In contrast, 87 proteins $(7.7 \%)$ were detected in all three SSc groups, but were absent in controls (Fig. 1e; Additional file 2: Table S2). Functional analyses of these proteins revealed strong enrichment of proteins involved in oxidative stress responses and nucleic acid processing (Additional file 3: Table S3B).

Of the 1,130 non-redundant proteins identified, 473 $(41.8 \%)$ were unique to a given autoantibody group (Fig. 1f); however, the vast majority of these proteins were exclusive to a single patient, with only 111 (23.5\%) detected in two or more patients. These results suggest a wide range of autoantibody responses within each of the clinical autoantibody groups beyond what has already been described.

Among the major autoantibody groups, immunoprecipitation of RNAP3 was exclusive to the RNAP3 group, with no RNAP3 peptides detected in any of the other samples (Table 2). In contrast, TOP1 peptides were consistently highest among TOP1 patients, but were also detected at low levels in all four $\mathrm{RNAP}^{+}$patients, and in two controls (Table 2). As these patients were negative for TOP1 autoantibodies by clinical testing, these results indicate a higher degree of sensitivity for our IP/MS protocol compared to standard ELISA-based methods used clinically. In contrast, CENP was only 

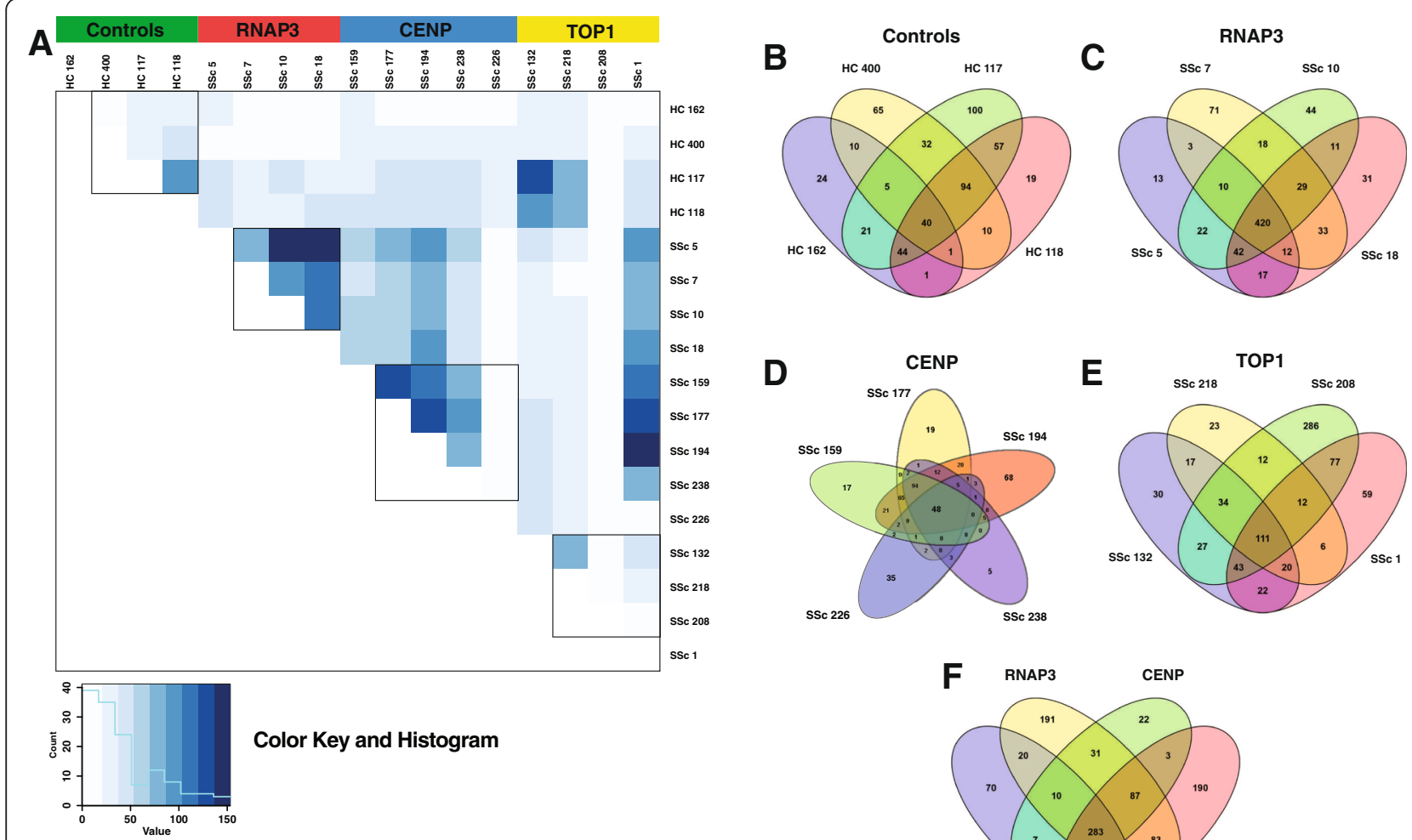

D

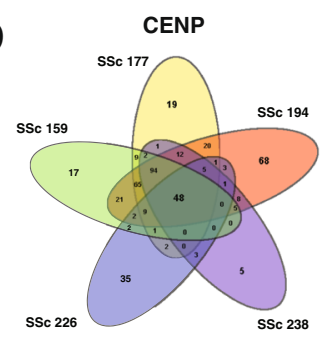

E

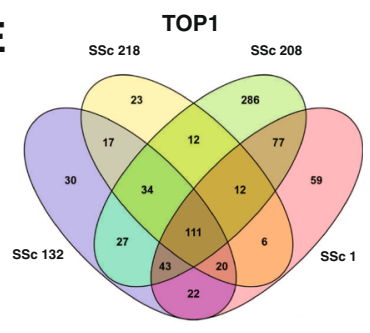

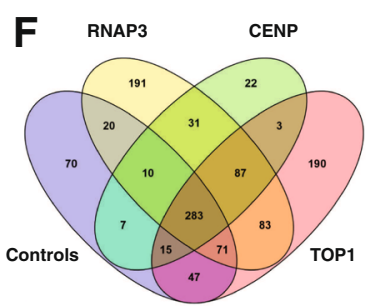

Fig. 1 Overview of mass spectrometry results. a Correlation matrix of non-redundant protein hits for all patients and controls. Comparisons were performed using Fisher's exact test with the Bonferroni correction. Black boxes indicate intra-group comparisons for each of the four clinically defined groups. Green controls; red RNA polymerase III (RNAP3); blue centromere protein (CENP); yellow topoisomerase I (TOP1). b-f Venn diagrams depict overlap in non-redundant peptide hits within and between groups. b healthy controls, c RNAP3, d CENP, e TOP1, and $\mathbf{f}$ overlap between groups

detected at low levels in the CENP group, likely because it remained bound to the tightly packed centromere complex of chromatin.

Other known SSc autoantigens were also detected. RuvBL [18] was strongly detected in all SSc samples, while virtually absent in controls. $\mathrm{Ku}$ and $\mathrm{Su}$, along with a wide array of anti-tRNA synthetases [19] were routinely detected in both the RNAP3 and TOP1 subsets, but were only weakly present in the CENP and control groups (Table 2).

Several autoantigens previously implicated in SSc were found at low, background levels in both SSc and control samples. Ro52/TRIM21 [20] and nucleophosmin/B23 [21] were widely detected across all four groups, suggesting widespread reactivity to these proteins in SSc and controls. We did not find evidence in SSc of enrichment of $\mathrm{Pm} / \mathrm{Scl}$ autoantibodies, which target exosome components EXOSC1-10 [22]. Peptides for these proteins were absent in the CENP group, but were detected at low levels in other subsets, including controls. Autoantigens not detected here include many of the URNPs, PDGFR, matrix metalloproteinases, tissue plasminogen activator, and vascular receptor antibodies (Table 2).

\section{Functional clustering of identified proteins}

To identify functional interactions among autoantigens, all 763 non-redundant protein hits were submitted as a query to the GIANT global average network. This approach included both SSc-specific targets and those detected at background levels in controls, to better understand the full range of autoreactive proteins and complexes. Nine distinct communities were identified within the resulting network, in which each gene is represented by a node, and two genes share an edge if they are predicted to functionally interact (Additional file 4: Figure S1). Analysis of each of these communities by g:Profiler revealed functional enrichment for a wide range of biological processes associated with important disease processes and components (Additional file 4: Figure S1). Community 1 is dominated by ribosomal proteins, eukaryotic initiation factor 3 (eIF3) subunits, and includes the SSc autoantibody target nucleophos$\mathrm{min} / \mathrm{B} 23$. Communities 2 and 8 show strong enrichment for Gene Ontology (GO) terms mRNA processing, ribonucleoprotein complex, and cytosolic stress granule. Community 2 is dominated primarily by DEAD box 
Table 2 SSc-associated autoantibodies observed in this study

\begin{tabular}{|c|c|c|c|c|c|c|c|c|}
\hline \multirow[t]{2}{*}{ Alias } & \multirow[t]{2}{*}{ Associated proteins } & \multirow[t]{2}{*}{ Disease subset } & \multirow[t]{2}{*}{ Clinical associations } & \multicolumn{4}{|c|}{ Prevalence in this dataset (avg/freq) } & \multirow[t]{2}{*}{ Reference } \\
\hline & & & & Control $(n=4)$ & RNAP3 $(n=4)$ & TOP1 $(n=4)$ & $\operatorname{CENP}(n=5)$ & \\
\hline \multicolumn{9}{|l|}{ Major autoantibodies } \\
\hline RNA Pol III & POLR3A & dSSC & Renal crisis, cancer & - & $+++(28 / 4)$ & - & - & $\begin{array}{l}\text { Graf, et al. } 2012 \text { [1]; Mehra, } \\
\text { et al. } 2013 \text { [3] }\end{array}$ \\
\hline Scl70 & TOP1 & dSSC & $\begin{array}{l}\text { Poor prognosis, internal organ } \\
\text { involvement, and proteinuria }\end{array}$ & $+(3 / 2)$ & $+(4 / 4)$ & $+++(19 / 4)$ & - & Mehra, et al. 2013 [3] \\
\hline Centromere & CENPB, CENPH & ISSC/CREST & PAH, ILD & - & - & - & $+(1 / 2)$ & Mehra, et al. 2013 [3] \\
\hline \multicolumn{9}{|c|}{ Other SSC autoantibodies present in our dataset } \\
\hline Endothelial Cell & TUBB, VCL, LMNA, RPLPO & SSC & $\mathrm{PAH}$ & $+(1 / 1)$ & $++(6 / 4)$ & $+(4 / 2)$ & $+(0 / 1)$ & $\begin{array}{l}\text { Dib, et al. } 2012 \text { [34], Naniwa, } \\
\text { et al. } 2007 \text { [35] }\end{array}$ \\
\hline Fibroblast & $\begin{array}{l}\text { ENO1, G6PD, HSPA1A, } \\
\text { HSPA1B, VIM }\end{array}$ & SSC & $\mathrm{PAH}$ & $+(3 / 4)$ & $+++(12 / 4)$ & $++(5 / 3)$ & $++(8 / 5)$ & $\begin{array}{l}\text { Terrier, et al. } 2008 \text { [36], } \\
\text { Terrier, et al. } 2009 \text { [37] }\end{array}$ \\
\hline Histone & H1FX, HIST1H1B, HIST1H4A & SSC & $\begin{array}{l}\text { PF, internal organ involvement, } \\
\text { decreased survival }\end{array}$ & $+(1 / 1)$ & $+(3 / 3)$ & $+(1 / 1)$ & - & Mehra, et al. 2013 [3] \\
\hline B23 & NPM1 & dSSC, CENP- ISSC & $\mathrm{PAH}$ & $+(4 / 4)$ & $++(7 / 4)$ & $++(5 / 4)$ & $++(6 / 5)$ & Mehra, et al. 2013 [3] \\
\hline $\mathrm{Ku}$ & XRCC5, XRCC6 & ISSC & Myositis & $+(3 / 3)$ & $+++(12 / 4)$ & $++(8 / 4)$ & $+(2 / 3)$ & $\begin{array}{l}\text { Graf, et al. } 2012 \text { [1]; Mehra, } \\
\text { et al. } 2013 \text { [3] }\end{array}$ \\
\hline Su & AGO2 & $\mathrm{SSC}, \mathrm{PM} / \mathrm{Scl}$ & Unknown & - & $+(1 / 2)$ & $+(3 / 1)$ & - & Satoh, et al. 2013 [38] \\
\hline Mitochondrial (M2) & DLD, PDHB & ISSC & $\begin{array}{l}\text { Strong association with primary } \\
\text { biliary cirrhosis }\end{array}$ & $+(1 / 1)$ & $+(2 / 3)$ & $+(1 / 1)$ & - & Mehra, et al. 2013 [13] \\
\hline $\mathrm{Pm} / \mathrm{Scl}$ & EXOSC1-10 & SSC & $\begin{array}{l}\mathrm{PF} \text {, digital ulcers; decreased risk } \\
\text { of PAH and Gl symptoms }\end{array}$ & $+(2 / 2)$ & $++(5 / 3)$ & $+(2 / 2)$ & - & Mehra, et al. 2013 [13] \\
\hline hnRNPs & HNRNPA1-3, HNRNPL & SSC & Common in SARDs & $+(0 / 1)$ & $++(7 / 4)$ & $+(3 / 4)$ & $+(2 / 4)$ & Siapka, et al. 2007 [39] \\
\hline U1 & SNRNPA，SPRNP70 & SSC & $\begin{array}{l}\text { Co-occurrence with SS-A/SS-B, } \\
\text { PAH, overlap syndrome }\end{array}$ & - & $+(2 / 4)$ & $+(1 / 2)$ & $+(0 / 1)$ & $\begin{array}{l}\text { Graf, et al. } 2012 \text { [1]; Mehra, } \\
\text { et al. } 2013 \text { [3] }\end{array}$ \\
\hline U5 & SNRNP200 & $\mathrm{SSC}, \mathrm{PM} / \mathrm{SCl}$ & Unknown & $++(6 / 3)$ & $++(9 / 4)$ & $++(8 / 3)$ & $+(1 / 2)$ & Kubo, et al. 2002 [40] \\
\hline RO52/TRIM21 & TRIM21 & SSC & ILD, other autoimmune diseases & $++(6 / 3)$ & $+++(12 / 4)$ & $++(6 / 4)$ & $++(8 / 4)$ & Mehra, et al. 2013 [3] \\
\hline RuvB & RUVBL1, RUVBL2 & dSSC & $\begin{array}{l}\text { Common in SARDs, older age at } \\
\text { onset, male sex }\end{array}$ & $+(1 / 1)$ & $++(7 / 4)$ & $+(3 / 4)$ & $+(2 / 4)$ & Kaji, et al. 2014 [18] \\
\hline Annexin V & ANXA5 & dSSC, CENP- ISSC & Digital ischemia & $+(2 / 2)$ & $++(7 / 4)$ & $+(4 / 3)$ & $+(3 / 4)$ & Mehra, et al. 2013 [3] \\
\hline SS-B/LA & SS-A, SS-B & SSC & ILD, other autoimmune diseases & - & $+(3 / 4)$ & $+(2 / 2)$ & $+(0 / 1)$ & Mehra, et al. 2013 [3] \\
\hline Peroxiredoxin & PRDX1 & SSC & $\begin{array}{l}\text { Disease duration, } \mathrm{PF} \text {, cardiac } \\
\text { involvement, TOP1+ patients }\end{array}$ & $+(2 / 4)$ & $++(8 / 4)$ & $+(3 / 3)$ & $+(4 / 4)$ & Mehra, et al. 2013 [3] \\
\hline hUBF/NOP90 & UBTF & ISSC & $\begin{array}{l}\text { Mild organ involvement, } \\
\text { favorable prognosis }\end{array}$ & - & $+(1 / 2)$ & - & - & Mehra, et al. 2013 [3] \\
\hline Th/To & POP1 & ISSC & $\begin{array}{l}\text { PF, renal crisis, poor prognosis, } \\
\text { myositis, PAH }\end{array}$ & $+(1 / 2)$ & $+(1 / 1)$ & $+(3 / 3)$ & - & $\begin{array}{l}\text { Graf, et al. } 2012 \text { [1]; Mehra, } \\
\text { et al. } 2013 \text { [3] }\end{array}$ \\
\hline
\end{tabular}


Table 2 SSc-associated autoantibodies observed in this study (Continued)

\begin{tabular}{|c|c|c|c|c|c|c|c|c|}
\hline PL-12 & AARS & SSC, PM/DM & ILD without myositis & - & - & $+(1 / 1)$ & $+(1 / 1)$ & Hamaguchi, et al. 2013 [19] \\
\hline OJ & IARS & SSC, PM/DM & ILD without myositis & $+(1 / 1)$ & - & $+(3 / 3)$ & - & Hamaguchi, et al. 2013 [19] \\
\hline EJ & GARS & SSC, PM/DM & ILD, myositis & - & $+(3 / 4)$ & $+(2 / 2)$ & $+(0 / 1)$ & Hamaguchi, et al. 2013 [19] \\
\hline Jo-1 & HARS & SSC, PM/DM & ILD, myositis & - & $+(1 / 4)$ & - & - & Hamaguchi, et al. 2013 [19] \\
\hline PL-7 & TARS & SSC, PM/DM & ILD, myositis & $+(2 / 2)$ & $++(8 / 4)$ & $++(6 / 4)$ & $+(2 / 4)$ & Hamaguchi, et al. 2013 [19] \\
\hline $\mathrm{Ha}$ & YARS & SSC, PM/DM & Interstitial pneumonia & - & $+(0 / 1)$ & - & - & Hashish, et al 2005 [41] \\
\hline Zo & FARSA, FARSB & $\mathrm{SSC}, \mathrm{PM} / \mathrm{SCl}$ & Anti-synthetase syndrome & - & $+(2 / 4)$ & - & - & Betteridge, et al. 2007 [42] \\
\hline \multicolumn{9}{|c|}{ SSC autoantibodies not detected in our dataset } \\
\hline Fibrillarin & U3RNP & dSSC & $\begin{array}{l}\text { More frequent in blacks; severe } \\
\text { disease, poor prognosis }\end{array}$ & - & - & - & - & Mehra, et al. 2013 [3] \\
\hline U11/U12 RNP & SNRNP35 & SSC & $\begin{array}{l}\text { Lung fibrosis, gastrointestinal } \\
\text { involvement }\end{array}$ & - & - & - & - & Mimori, 1999 [43] \\
\hline PDGFR & PDGFR & SSC & Unknown & - & - & - & - & $\begin{array}{l}\text { Svegliati Baroni, et al. } \\
2006 \text { [44] }\end{array}$ \\
\hline MMP & MMP family & dSSC & Skin, lung, and vascular fibrosis & - & - & - & - & Mehra, et al. 2013 [3] \\
\hline tPA & PLAT & ISSC & $\mathrm{PAH}$ & - & - & - & - & Mehra, et al. 2013 [3] \\
\hline$|F| 16$ & $|F| 16$ & ISSC & Common in SARDs & - & - & - & - & Mehra, et al. 2013 [3] \\
\hline Fibrillin 1 & FBN1 & dSSC & $\begin{array}{l}\text { Choctaw and Japanese patients; } \\
\text { absent in Caucasians }\end{array}$ & - & - & - & - & Mehra, et al. 2013 [3] \\
\hline Vascular Receptors & AGTR2, EDN1 & SSC & TOP1+ patients, renal crisis & - & - & - & - & Mehra, et al. 2013 [3] \\
\hline ATF2 & ATF2 & SSC & $\begin{array}{l}\text { Longer disease duration, } \\
\text { decreased lung function }\end{array}$ & - & - & - & - & Mehra, et al. 2013 [3] \\
\hline
\end{tabular}

Data are presented as the average of all peptide hits across each autoantibody group, followed by the frequency of peptide detection within the group. For autoantibodies known to target more than one protein or subunit, data for a single representative protein are shown, with the specific protein highlighted in bold. Associated proteins indicate specific protein targets identified in this study; among autoantibodies not identified here, the most common targets are listed. Symbols:,,-+++ , and +++ indicate an average of $0,1-4,5-9$, and $\geq 10$ peptide hits per group, respectively

SSC systemic sclerosis, ISSC limited cutaneous SSC, dSSC diffuse cutaneous SSc, PAH pulmonary arterial hypertension; ILD interstitial lung disease; CREST CREST syndrome (calcinosis, Raynaud phenomenon, esophageal SSc systemic sclerosis, $I S S C$ limited cutaneous SSC, $1 S S C$ diffuse cutaneous SSC, PAH pulmonary arterial hypertension; $1 L D$ int 
helicases proteins, while community 8 contains a diverse array of proteins including multiple SSc autoantibodies, including TOP1, SSB, $\mathrm{Pm} / \mathrm{Scl}$ proteins, URNPs, and HNRNPs, and numerous serine/arginine-rich splicing factors. Community 3 consists primarily of aminoacyl tRNA synthetases, a cluster often targeted in autoimmune diseases $[19,23]$. Communities 4,5 , and 9 are strongly associated with a variety of $\mathrm{GO}$ processes known to play a major role in SSc, including wound healing, IFN signaling, and response to oxidative stress. Major proteins include CD44, HLAs, myosins, and filamin proteins in community 4 and tricarboxylic acid cycle proteins in community 5 . Community 9 contains multiple protein disulfide isomerases and peroxiredoxins, protein folding enzymes such as calnexin (CANX) and calreticulin (CALR), and the major collagen processing enzyme prolyl 4-hydroxylase beta (P4HB). Community 6 contains multiple annexin and 14-3-3 proteins; enriched GO processes include ribonucleoprotein complex assembly, mitochondrial transport, RNA processing, and anchoring junction. Community 7 associated with GO terms include cell cycle, RNA polymerase III complex, DNA-PK-Ku complex, and antigen processing and presentation. Community 7 includes several SSc autoantibody targets including $\mathrm{Ku}$ proteins XRCC5 and 6, RUVBL1 and 2, RNA polymerase I and II subunits, multiple proteasomal subunits, and T-complex proteins.

\section{Preferential detection of autoantibodies in SSC}

Subsequent comparisons between groups were performed in a semiquantitative manner based on the presence or absence of a given protein in an immunoprecipitant, with quantitative analyses limited to comparisons within an individual sample. To identify biological processes and cellular components differentially targeted in SSc, with minimal to no background detection in controls, we examined all proteins detected in $>50 \%$ of SSc samples at a frequency $>1.5$-fold relative to controls, resulting in a list of 137 differentially detected proteins (Fig. 2; Additional file 2: Table S2). Enriched biological processes included $n c R N A$ metabolic process, response to oxygen radical, and triglyceride-rich lipoprotein particle remodeling. Preferentially targeted cellular components include cytosolic stress granule, lipid-protein complex, pigment granule, and anchoring junction; molecular functions include antioxidant activity and mRNA binding (Additional file 3: Table S3C).

\section{RNA processing centers are major targets of SSC autoantibodies}

The strong enrichment for GO terms associated with mRNA processing and stress response, as well as the identification of cytosolic stress granule as an enriched cellular component, led us to further investigate the role of stress granules (SG) and RNA processing bodies (PB) in the autoantibody response of SSc. SG and PB represent distinct, non-membranous cytoplasmic entities, which arise in response to different cellular stresses including oxidative stress, hypoxia, viral infection, unfolded proteins, and amino acid deprivation [24]. These structures exist in constant flux, driven by the availability of constituent mRNPs, regulating the fate of untranslated mRNAs in response to translational arrest [25]. While SG are generally absent under normal conditions, PB are constitutively present at low levels due to their role as microRNA processing centers. Both structures have been shown to arise in response to cellular stresses, including oxidative stress, ischemia, and cancer [26], all of which are known to be important in SSc pathogenesis [5, 27].

In addition to the 137 differentially detected proteins described above, a wide range of $\mathrm{PB} / \mathrm{SG}$ constituents were readily detected across most SSc samples (Additional file 5: Table S4). Substantial reactivity was seen against PB components such as UPF1 and MOV10, and SG proteins FXR1 and FXR2, G3BP1 and G3BP2, and USP10. Only background levels of reactivity were seen in healthy controls.

\section{Validation of $\mathrm{PB} / \mathrm{SG}$ antibodies in SSC}

In order to validate the differential abundance of $\mathrm{PB} / \mathrm{SG}$ proteins identified by LC-MS/MS, HeLa whole cell lysates were immunoprecipitated using antibodies from each patient as described in the LC-MS/MS analyses. Western blots were performed by resolving equal volumes of IP eluates by SDS-PAGE and transferring to nitrocellulose. Blots were then probed with antibodies targeting PB/SG proteins UPF1, MOV10, CAPRIN1, G3BP1, and USP10. These targets were chosen based upon their high level of detection across SSc groups, as determined based on our LC-MS/MS data. Strong reactivity was seen against all five proteins in SSc with only trace levels detected in controls (Fig. 3a), indicating widespread immune responses against these protein complexes.

Further validation was performed using immunofluorescence (IF) staining of U2OS cells maintained under conditions of oxidative stress to induce PB/SG formation. Cells were probed with patient sera in combination with PB and SG markers SK1-Hedls and eIF3b, respectively. Co-localization between patient sera and PB/SG markers was observed in six of nine SSc patients, with at least one positive sample in each of the three autoantibody groups; no staining was seen for any of the three healthy controls (Fig. 3b). These results are consistent with that seen on LC-MS/MS, particularly among RNAP3 patients, who exhibited the strongest and most consistent autoantibody responses across both methods. Taken together, these data strongly implicate PB/SG as novel targets of SSc autoantibody responses. 


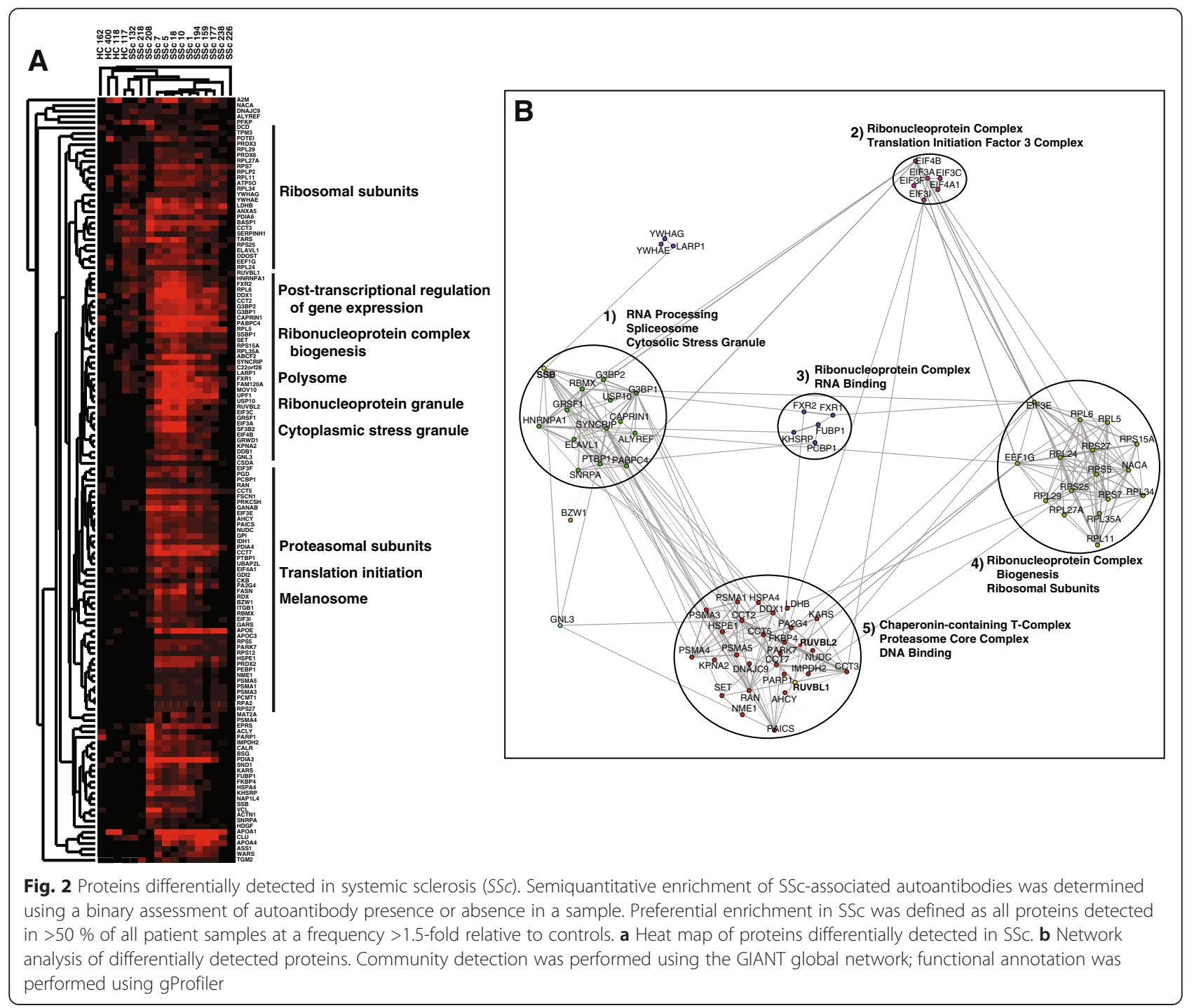

\section{Discussion}

Autoantibodies have long been used in the diagnosis of SSc, with different autoantibodies predictive of clinical outcomes, including interstitial lung disease, pulmonary arterial hypertension, and skin involvement. While a wide array of SSc-associated autoantibodies have been described, diagnoses are often performed based upon the presence or absence of reactivity against three proteins: RNAP3, TOP1, and CENP. The data presented here suggest a much broader autoantibody response, which is reflective of underlying disease pathologies. Strong subset-specific reactivity was evident against both RNAP3 and TOP1, with no RNAP3 peptides detected in any of the other groups; however, all four RNAP3 patients exhibited modest reactivity against TOP1, indicating a degree of overlap between these two autoantibody groups. When peptides recovered are extended beyond the three major targets, we found substantial overlap across the three major SSc groups. We found peptides from the autoantigens of RuvBL1/2, which appear to act as general markers of SSc, with consistent detection across all SSc groups, with almost no reactivity seen in controls. In contrast, some common SSc autoantigens such as B23 and Ro52/TRIM21 were recovered in virtually all samples, and in controls, indicating an important degree of baseline reactivity against some of the more common autoantibody targets.

In this proof-of-concept study, we do not attempt to address the clinical implications of the autoantibody responses described here due to the limited number of patients analyzed, nor are we able to speculate on the presence or absence of these autoantibodies in other SSc autoantibody groups. Our depth in this study comes from the number of potential antigens analyzed, which cover the full proteome. Future studies examining a much larger cohort of SSc patients, along with representatives of other 


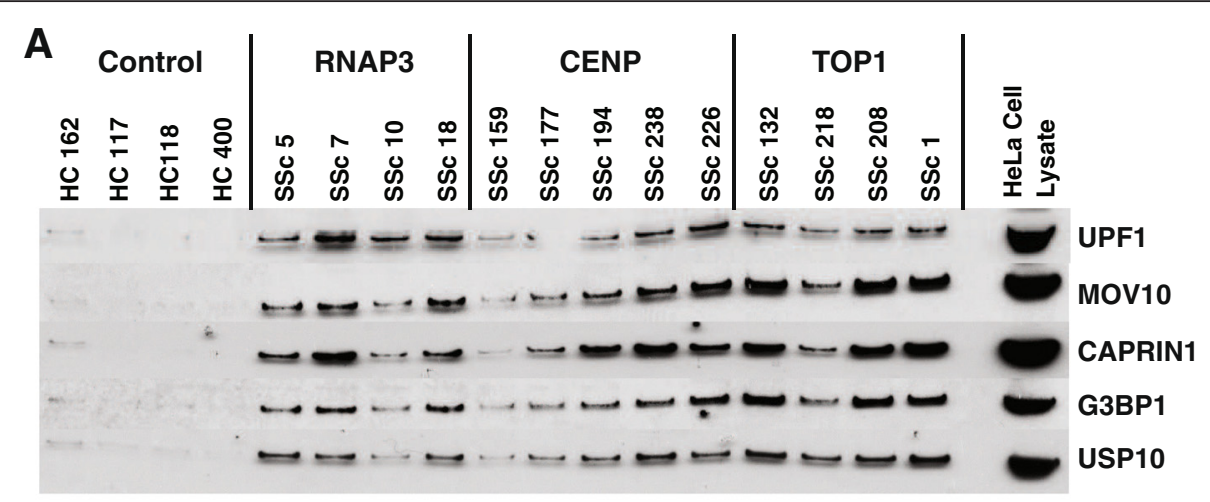

B

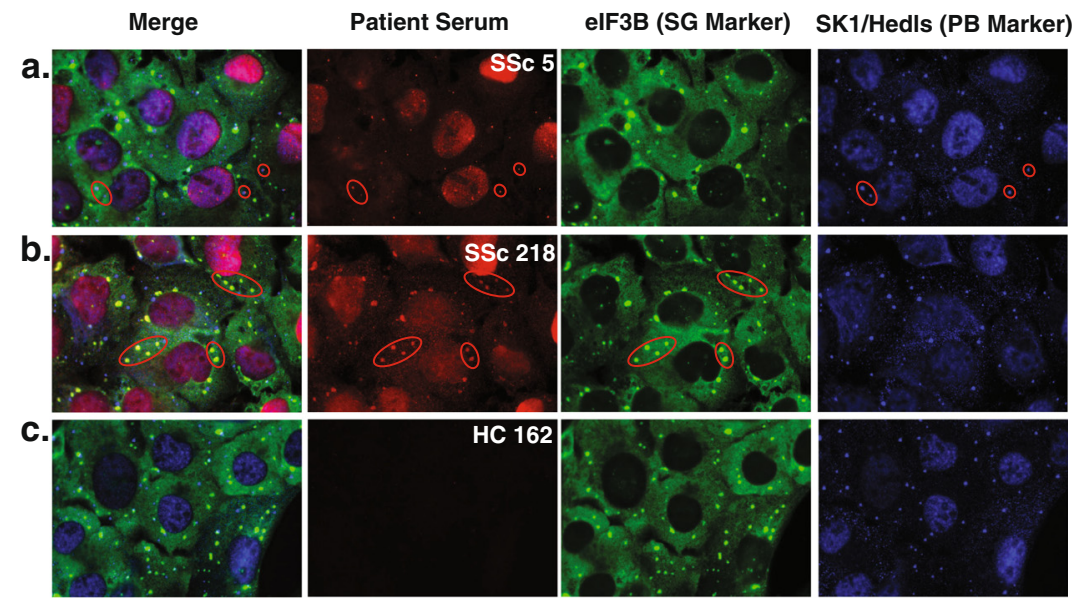

Fig. 3 Validation of RNA processing bodies $(P B) /$ stress granules $(S G)$ as a target of the SSC autoimmune response. a HeLa cell lysates were immunoprecipitated using patient sera, resolved by SDS-PAGE, and probed with antibodies targeting known PB and SG proteins; HeLa whole cell lysate was used as a control. b Immunofluorescence was performed in U2OS cells treated with sodium (meta)arsenite to induce the formation of SG. Cells were then fixed with $4 \%$ paraformaldehyde and permeabilized with $5 \%$ normal horse serum and $0.1 \%$ digitonin in Tris-buffered saline. Staining was performed with anti-elF3b (SG marker), anti-SK1-Hedls (PB marker), and patient sera. Representative images depicting co-localization between patient sera and SG/PB markers are shown, with sites of co-localization circled in red. RNAP RNA polymerase, CENP centromere protein TOPI topoisomerase I

autoimmune diseases, will be necessary to determine the clinical value of these potential autoantibodies.

This is not the first study to suggest the presence of multiple autoantibodies in SSc. Immunoassays performed by Op De Beeck, et al. revealed the presence of multiple autoantibodies in a small subset of SSc patients [28]. A similar analysis by Graf et al. using the EUROLINE immunoassay revealed the presence of multiple autoantibodies in $11 \%$ of patients [1].

Autoantibodies against extracellular immune signaling receptors and extracellular matrix proteins were conspicuously absent in these data; this includes the absence of numerous autoantibodies previously implicated in SSc pathogenesis, such as anti-fibrillin 1, anti-MMP, and anti-PDGFR [29]. Additional analyses in other cell types, such as fibroblasts or endothelial cells, and cells maintained under physiologically relevant growth conditions, such as immune activation or oxidative stress, may be useful for identifying other proteins and complexes which may play a role in disease pathogenesis.

In addition to identifying novel autoantibody targets, the unbiased nature of mass spectrometry provides additional insights into the processes potentially underlying autoimmunity. The preferential detection of proteins associated with RNA processing and oxidative stress as a general feature of SSc autoantibodies may be indicative of their origins. Combined with the consistent targeting of $\mathrm{PB} / \mathrm{SG}$ described here spanning all SSc patients, these data suggest a basic model in which disease-specific pathologies give rise to specific autoantibodies. Strong induction of SGs is observed in response to cellular stresses, including oxidative stress and ischemia, two well-established phenomena in SSc [27]. SG/PB are also readily induced in response to the tumor microenvironment, consistent with recent evidence linking RNAP3positive SSc and cancer $[5,30]$. Combined with evidence 
linking transforming growth factor (TGF)- $\beta$ signaling with an increase in PB formation [31], many of the major processes underlying SSc pathogenesis appear broadly consistent with an immune response against cells undergoing a stress response. PBs are also known to associate with other cytoplasmic structures, such as $\mathrm{U}$ bodies [32], which house an number of well-established SSc autoantibody targets, including U1, U5, and U11/U12. Taken together, these data suggest a model in which autoantibodies arise as a secondary phenotype in response to SSc-related processes already underway.

Some evidence suggesting a link between PBs and autoimmunity has been described previously. Bhanji, et al. observed reactivity against a number of PB-associated proteins, including GE1/Hedls, GW182, and Ago2 in a range of autoimmune diseases, including SSc [33]. Among these autoantigens, only Ago2 was also identified in this analysis, suggesting a persistent, yet diverse response against this complex. A similar analysis of SG-associated proteins has not been performed; however given the reactivity to PB proteins seen in other autoimmune diseases, reactivity in other autoimmune diseases is possible. A detailed analysis using both mass spectrometry and other methods will be necessary to understand the degree to which autoantibodies to SG/PBs are seen in other autoimmune diseases, and the clinical implications of these findings.

This work has several limitations. First, we cannot eliminate the possibility that some proteins found in our mass spectrometry data result from co-IP of multiprotein complexes by a single autoantibody; however, we were able to confirm the presence of multiple $\mathrm{PB} / \mathrm{SG}$ autoantibodies by other means (Fig. 3). We also cannot rule out the possibility that some targets were missed due to their being sequestered into tightly packed molecular complexes associated with chromatin. For example, the presence of CENP autoantibodies within these samples had been established using clinical methods, indicating its absence in our mass spectrometry data is likely a result of its sequestration into large macromolecular complexes with limited solubility. A lack of age- and gender-matched controls likely underestimates the degree of baseline reactivity seen in unaffected controls. Finally, the small number of patient samples used in this study prevents any clinical interpretation, and the variability in the number of peptides recovered between experiments limits direct quantitative comparisons between autoantibody groups.

\section{Conclusions}

The data presented here provide evidence of diverse immune reactivities in SSc targeting a wide array of protein complexes. Among these complexes, autoantibodies targeting PB/SG were consistently identified across both clinical SSc subsets and major autoantibody groups, suggesting a potential novel autoantibody target. Taken together, these data suggest immune responses to proteins involved in cellular stress may be a common mechanism for autoantibody generation.

\section{Additional files}

\begin{abstract}
Additional file 1: Table S1. Complete list of peptides identified in this analysis. TP number of total peptides mapping to a protein, UP number of unique peptides mapping to a protein, UM number of non-redundant peptides mapping exclusively to a protein, MW molecular weight, Length protein length in amino acids. (XLS $639 \mathrm{~kb}$ )
\end{abstract}

Additional file 2: Table S2. Gene lists used in these analyses. (XLSX $17 \mathrm{~kb}$ )

Additional file 3: Table S3. Systemic sclerosis (SSc)-specific enrichment of processes and components. Proteins differentially detected in SSC were analyzed using gProfiler. Statistically significant processes and components are shown. A) Peptides detected at any level across all four groups. B) Peptides identified in all SSc groups, but absent in controls. C) Analysis of 137 proteins differentially detected in SSC. BP biological process, CC cellular component, MF molecular function, ke KEGG pathway, re REACTOME pathway. (ODS 70 kb)

Additional file 4: Figure S1. Network analysis of systemic sclerosis (SSc) autoantigens. All 763 non-redundant peptide hits identified in two or more patients were analyzed using the Genome-scale Integrated Analysis of gene Networks in Tissues (GIANT) global network to identify functionally associated protein networks. Analysis of community function was performed using gProfiler. SSc-associated autoantibodies are highlighted in yellow. (EPS $1902 \mathrm{~kb}$ )

Additional file 5: Table S4. Processing body and stress granule proteins identified in this analysis. *Proteins with multiple subunits. Data indicate non-redundant peptide hits. (ODS 20 kb)

\section{Abbreviations}

CENP: centromere protein; DMEM: Dulbecco's modified Eagle's medium; dSSc: diffuse systemic sclerosis; ELISA: enzyme-linked immunosorbent assay; FBS: fetal bovine serum; GIANT: Genome-scale Integrated Analysis of gene Networks in Tissues; IFN: interferon; kDa: kiloDalton; LC-MS/MS: liquid chromatography tandem-mass spectrometry; IP: immunoprecipitation; ISSc: limited systemic sclerosis; PB: RNA processing bodies; PBS: phosphatebuffered saline; RNAP3: RNA polymerase III; SG: stress granules; SSc: systemic sclerosis; TOP1: topoisomerase I.

\section{Competing interests}

Dr. Whitfield has received royalties for patents regarding gene expression biomarkers in Scleroderma and is a scientific founder of Celdara Medical LLC. Dr. Lafyatis has received both grants and consulting fees from Genzyme/ Sanofi, Shire, Regeneron, Biogen, BMS, Inception, Precision Dermatology, PRISM, UCB, Pfizer and Roche/Genentech; he received consulting fees from Lycera, Novartis, Celgene, Amira, Celdara, Celltex, Dart Therapeutics, Idera, Intermune, Medimmune, Promedior, Zwitter, Actelion, EMD Serono, Akros, Extera, Reneo, Scholar Rock, and HGS. No authors have any non-financial conflicts of interest to report.

\section{Authors' contributions}

MEJ conceived of the study, performed experiments, analyzed data, and wrote the manuscript. AVG performed mass spectrometry and helped to revise the manuscript. JNT performed data analysis and helped to revise the manuscript. SML performed immunofluorescence experiments, and helped to revise the manuscript. DS performed mass spectrometry, and revised the manuscript. JKG, RFS, and RL provided clinical samples, and revised the manuscript. PJA designed experiments, provided technical assistance, and revised the manuscript. SAG and MLW conceived of the study, participated in its design, and helped to revise the manuscript. All authors read and approved the final manuscript. 


\section{Acknowledgements}

This work was supported by grants from the NIH National Institute of Arthritis and Musculoskeletal and Skin Diseases (NIAMS) Center of Research Translation (P50 AR060780 to MLW and RL), the Department of Defense (PR130908 to MLW), and a SYNERGY grant from the Geisel School of Medicine at Dartmouth (to MLW). JNT is supported in part by a grant from the National Institute of General Medical Sciences (NIGMS; T32GM008704). SAG is supported by grants R01-CA155260 and S10-OD016212 from the NIH. JKG is supported by a Kellen Foundation Clinician Scientist Development Award from the Hospital for Special Surgery. Written informed consent was obtained from all participants for publication of their individual details in this manuscript. All consent forms are held by the respective authors' institutions and are available for review by the Editor-in-Chief.

\section{Author details}

'Department of Genetics, Geisel School of Medicine at Dartmouth, Hanover, $\mathrm{NH}$, USA. 'Division of Rheumatology, Immunology, and Allergy, Brigham and Women's Hospital, Boston, MA, USA. ${ }^{3}$ Department of Rheumatology, Hospital for Special Surgery, New York, NY, USA. ${ }^{4}$ Boston University School of Medicine, Boston, MA, USA. ${ }^{5}$ Dartmouth Medical School, Hinman Box 7400, Hanover, NH 03755, USA.

\section{Received: 6 October 2015 Accepted: 3 January 2016}

Published online: 22 January 2016

\section{References}

1. Graf SW, Hakendorf P, Lester S, Patterson K, Walker JG, Smith MD, et al. South Australian Scleroderma Register: autoantibodies as predictive biomarkers of phenotype and outcome. Int J Rheum Dis. 2012;15:102-9.

2. Steen VD. Autoantibodies in systemic sclerosis. Semin Arthritis Rheum. 2005; 35:35-42.

3. Mehra S, Walker J, Patterson K, Fritzler MJ. Autoantibodies in systemic sclerosis. Autoimmun Rev. 2013;12:340-54

4. Fertig N, Domsic RT, Rodriguez-Reyna T, Kuwana M, Lucas M, Medsger TA, et al. Anti-U11/U12 RNP antibodies in systemic sclerosis: A new serologic marker associated with pulmonary fibrosis. Arthritis Care Res. 2009;61:958-65.

5. Joseph CG, Darrah E, Shah AA, Skora AD, Casciola-Rosen LA, Wigley FM, et al. Association of the autoimmune disease scleroderma with an immunologic response to cancer. Science. 2014;343:152-7.

6. Robinson WH, DiGennaro C, Hueber W, Haab BB, Kamachi M, Dean EJ, et al. Autoantigen microarrays for multiplex characterization of autoantibody responses. Nat Med. 2002;8:295-301.

7. Yore MM, Kettenbach AN, Sporn MB, Gerber SA, Liby KT. Proteomic analysis shows synthetic oleanane triterpenoid binds to mTOR. PLoS ONE. 2011;6:e22862

8. Eng JK, Jahan TA, Hoopmann MR. Comet: An open-source MS/MS sequence database search tool. Proteomics. 2013;13:22-4.

9. Hsieh EJ, Hoopmann MR, MacLean B, MacCoss MJ. Comparison of database search strategies for high precursor mass accuracy MS/MS data. J Proteome Res. 2009:9:1138-43.

10. Elias JE, Gygi SP. Target-decoy search strategy for increased confidence in large-scale protein identifications by mass spectrometry. Nat Methods. 2007:4:207-14.

11. Oliveros JC. VENNY. An interactive tool for comparing lists with Venn Diagrams. 2007.

12. Greene CS, Krishnan A, Wong AK, Ricciotti E, Zelaya RA, Himmelstein DS, et al. Zaslavsky E. Understanding multicellular function and disease with human tissue-specific networks. Nat Genet. 2015;47:569-76.

13. Shannon P, Markiel A, Ozier O, Baliga NS, Wang JT, Ramage D, et al. Cytoscape: a software environment for integrated models of biomolecular interaction networks. Genome Res. 2003;13:2498-504.

14. Reimand J, Arak T, Vilo J. g: Profiler - a web server for functional interpretation of gene lists (2011 update). Nucleic Acids Res. 2011;39:W307-15.

15. Eisen MB, Spellman PT, Brown PO, Botstein D. Cluster analysis and display of genome-wide expression patterns. PNAS. 1998;95:14863-8.

16. Saldanha AJ. Java Treeview - extensible visualization of microarray data. Bioinformatics. 2004;20:3246-8.

17. Novoradovskaya N, Perou C, Whitfield M, Basehore S, Pesich R, Aprelikova O, et al.: Universal human, mouse and rat reference RNA as standards for microarray experiments. In: Mol Bio Cell: 2002: Amer Soc Cell Biology 8120 Woodmont Ave, STE 750, Bethesda, MD 20814-2755 USA; 2002: 241A-241A.
18. Kaji K, Fertig N, Medsger TA, Satoh T, Hoshino K, Hamaguchi Y, et al. Autoantibodies to RuvBL1 and RuvBL2: A novel systemic sclerosis-related antibody associated with diffuse cutaneous and skeletal muscle involvement. Arthr Care Res. 2014:66:575-84.

19. Hamaguchi Y, Fujimoto M, Matsushita T, Kaji K, Komura K, Hasegawa M, et al. Common and Distinct Clinical Features in Adult Patients with Anti-Aminoacyl-tRNA Synthetase Antibodies: Heterogeneity within the Syndrome. PLoS ONE. 2013;8:e60442.

20. Fujimoto M, Shimozuma M, Yazawa N, Kubo M, Ihn H, Sato S, et al. Prevalence and clinical relevance of 52-kDa and 60-kDa Ro/SS-A autoantibodies in Japanese patients with systemic sclerosis. Ann Rheum Dis. 1997;56:667-70.

21. Ulanet DB, Wigley FM, Gelber AC, Rosen A. Autoantibodies against B23, a nucleolar phosphoprotein, occur in scleroderma and are associated with pulmonary hypertension. Arth Care Res. 2003;49:85-92.

22. Brouwer R, Vree Egberts WTM, Hengstman GJD, Raijmakers R, van Engelen BGM, Peter Seelig $H$, et al. Autoantibodies directed to novel components of the PM/Scl complex, the human exosome. Arth Res. 2002:4:134-8.

23. Lega J-C, Fabien N, Reynaud Q, Durieu I, Durupt S, Dutertre M, et al. The clinical phenotype associated with myositis-specific and associated autoantibodies: A meta-analysis revisiting the so-called antisynthetase syndrome. Autoimmun Rev. 2014;13:883-91.

24. Kedersha N, Ivanov P, Anderson P. Stress granules and cell signaling: more than just a passing phase? Trends Biochem Sci. 2013;38:494-506.

25. Kedersha N, Anderson P. Regulation of translation by stress granules and processing bodies. Prog Mol Biol Transl Sci. 2009;90:155-185.

26. Anderson P, Kedersha N. Stress granules: the Tao of RNA triage. Trends Biochem Sci. 2008;33:141-50.

27. Katsumoto TR, Whitfield ML, Connolly MK. The pathogenesis of systemic sclerosis. Annu Rev Pathol-Mech. 2011;6:509-37.

28. Op De Beéck K, Vermeersch P, Verschueren P, Westhovens R, Mariën G, Blockmans D, et al. Antinuclear antibody detection by automated multiplex immunoassay in untreated patients at the time of diagnosis. Autoimmun Rev. 2012;12:137-43.

29. Chung L, Utz P. Antibodies in scleroderma: Direct pathogenicity and phenotypic associations. Curr Rheumatol Rep. 2004;6:156-63.

30. Anderson P, Kedersha N, Ivanov P. Stress granules, P-bodies and cancer. Biochim Biophys Acta. 2015, 1849, 861-870.

31. Blanco FF, Sanduja S, Deane NG, Blackshear PJ, Dixon DA. Transforming growth factor $\beta$ regulates $P$-body formation through induction of the mRNA decay factor tristetraprolin. Mol Cell Bio. 2014;34:180-95.

32. Liu J-L, Gall JG. U bodies are cytoplasmic structures that contain uridine-rich small nuclear ribonucleoproteins and associate with P bodies. PNAS. 2007; 104:11655-9.

33. Bhanji RA, Eystathioy T, Chan EKL, Bloch DB, Fritzler MJ. Clinical and serological features of patients with autoantibodies to GW/P bodies. Clin Immunol. 2007;125:247-56.

34. Dib H, Tamby MC, Bussone G, Regent A, Berezné A, Lafine C, Broussard C, Simonneau G, Guillevin L, Witko-Sarsat V, et al. Targets of anti-endothelial cell antibodies in pulmonary hypertension and scleroderma. Eur Respir J. 2012;39(6):1405-1414.

35. Naniwa T, Sugiura Y, Banno S, Yoshinouchi T, Matsumoto Y, Ueda R. Ribosomal $\mathrm{P}$ protein $\mathrm{P} 0$ as a candidate for the target antigen of antiendothelial cell antibodies in mixed connective tissue. Clin Exp Rheumatol. 2007;25:593-598.

36. Terrier B, Tamby MC, Camoin L, Guilpain P, Broussard C, Bussone G, et al. Identification of target antigens of antifibroblast antibodies in pulmonary arterial hypertension. Am J Resp Crit Care Med. 2008;177(10):1128-1134

37. Terrier B, Tamby MC, Camoin L, Guilpain P, Bérézné A, Tamas N, et al. Anti-fibroblast antibodies from systemic sclerosis patients bind to a-enolase and are associated with interstitial lung disease. Ann Rheum Dis. 2009.

38. Satoh M, Chan JY, Ceribelli A, del-Mercado MV, Chan EK. Autoantibodies to Argonaute 2 (Su antigen). In: Ten Years of Progress in GW/P Body Research. Springer. 2013:45-59.

39. Siapka S, Patrinou-Georgoula M, Vlachoyiannopoulos PG, Guialis A. Multiple specificities of autoantibodies against hnRNP A/B proteins in systemic rheumatic diseases and hnRNP $L$ as an associated novel autoantigen. Autoimmunity. 2007:40(3):223-233.

40. Kubo M, Ihn H, Kuwana M, Asano Y, Tamaki T, Yamane K, Tamaki K. Anti-U5 snRNP antibody as a possible serological marker for scleroderma-polymyositis overlap. Rheumatol. 2002;41(5):531-534. 
41. Hashish L, Trieu E, Sadanandan P, Targoff I. Identification of autoantibodies to tyrosyl-tRNA synthetase in dermatomyositis with features consistent with anti-synthetase syndrome. In: Arthritis Rheum. 2005; 2005: S312-S312

42. Betteridge Z, Gunawardena H, North J, Slinn J, McHugh N. Anti-synthetase syndrome: a new autoantibody to phenylalanyl transfer RNA synthetase (anti-Zo) associated with polymyositis and interstitial pneumonia. Rheumatol. 2007:46(6):1005-1008.

43. Mimori T. Autoantibodies in Connective Tissue Diseases. Clinical Significance and Analysis of Target Autoantigens. Internal Med. 1999;38(7):523-532.

44. Svegliati BS, Santillo M, Bevilacqua F, Luchetti M, Spadoni T, Mancini M, et al. Stimulatory autoantibodies to the PDGF receptor in systemic sclerosis. N Engl J Med. 2006;354(25):2667-2676.

Submit your next manuscript to BioMed Central and we will help you at every step:

- We accept pre-submission inquiries

- Our selector tool helps you to find the most relevant journal

- We provide round the clock customer support

- Convenient online submission

- Thorough peer review

- Inclusion in PubMed and all major indexing services

- Maximum visibility for your research

Submit your manuscript at www.biomedcentral.com/submit
() BioMed Central 